\title{
sciendo
}

\section{Some Considerations on the Assessment of Learning in Higher Education}

\author{
Cătălin-Valeriu CURMEI \\ Bucharest University of Economic Studies, Bucharest, Romania \\ catalin.curmei@fabiz.ase.ro
}

\begin{abstract}
This paper deals with presenting the main aspects of the assessment of learning in higher education, with an emphasis on the challenges that the evolution of the society imposed to this process. The main assessment techniques are presented and explained, insisting on their ability of coping with different objectives that can be assumed by the evaluation process. The paper insists on the importance of choosing the adequate methods for the assessment of learning and on the need to create new ones able to fit better to the needs of the new generations. It also tackles the limits of using these methods and the nexus generated by the conflict between adopting the optimal methods for the assessment of learning from a scientific point of view and the need for imposing working procedures and standards in the higher education system that sometimes prevent from achieving the optimum. Also, the factors that have a role to play in the choice of the design of the assessment of learning process are described in a special section. The paper also insists on the need of creating a versatile assessment of learning process that would offer the right combination of assessment methods able to support the learning process and that can be achieved only if a large liberty is given to the professional judgement of the teachers as opposed to bureaucratical procedures imposed by the society.
\end{abstract}

Keywords: assessment of learning, assessment for learning, feedback, competence, assessment methods

\section{Introduction}

The fast progress of the information technology and the changes in the society as a whole, impose reforms in the education field, too. The expectations of the society regarding the outcome of the education system change, being in line with the progress in diverse fields of industry, technology and science that resulted, among others, in different preferences manifested by employers. Besides a higher level of average education among the workforce, more specific abilities and a higher degree of specialization are required. They must be also completed with personal skills such as team working, time management, stress management, flexibility and ability to adapt to novelties etc. The higher education system is nowadays expected to provide skilled working force in response to the needs of the labour market. To that purpose, the higher education system also implements changes in terms of curricula, teaching techniques, types of instruments used for facilitating learning and in terms of assessment of learning (Lile and Bran, 2014).

The present study aims at providing an overview of the main concepts in the assessment of learning in higher education, also explaining some of the particularities and limits of its implementation in practice.

Our approach has as a departure point the study of the relevant literature regarding the assessment of learning. The paper defines the main concepts put forward by the previous literature and explains the evolution of the assessment of learning with a special focus on the domain of the higher education. The goals of this process can be multiple and the teachers need to make a detailed planning of it before putting it at work in order to obtain the best outcome possible. The choice of the assessment strategy and techniques is therefore very important. This is why, the paper also makes an inventory of the main techniques used for the assessment of learning in higher education 
explaining the strengths and weaknesses of each of them and giving examples of how they may be combined and used in practice in order to optimally respond to specific goals of the assessment of learning process.

The paper also presents the author's view on the factors that have to be considered in the design of the assessment of learning process. When appropriate, it discusses the limits imposed on the outcome of the assessment of learning process by the reality of the Romanian higher education system.

The remaining of the paper is organized as follows. The following section presents a literature review on the assessment of learning in higher education focusing on the main concepts related to it and on the evolution of this process in time. The next section is concerned with the main techniques employed in the assessment of learning and how this process needs to be planned according to the specific objectives assumed. The next section is dedicated to exposing the author's opinion on the factors that influence the choice of the assessment strategy and on the limits of the use of this process in practice. The last section concludes.

\section{Literature review}

Calenda and Tammaro (2015) associate the assessment of learning with two aspects: the result understood as the learner's achievements and the process of learning reflecting how these achievements are acquired. In their opinion "Evaluating the formative product means to judge on the results of teaching and learning integrated process, whose effects can be controlled by considering the subject's specific performances". The assessment of learning needs to rely on the requirements that the labour market imposes to students. As a result, the content of the assessment of learning process recorded several evolution phases in time.

Schuwirth and van der Vleuten (in press) consider three phases of the evolution of the assessment of learning process which somehow correspond to the emergence of new requirements on the labour market. The first phase is the assessment as testing. According to the two authors, it corresponds to the period 1960-1970 in healthcare medical education when the unstructured evaluation has been appealed to include more objective assessment methods. The need emerged to create a strategy in which the tested abilities to be clearly defined, the assessment techniques to be unequivocal and to allow a smaller degree of subjectivity from the assessors' part. The assessment was expected to focus on a specific competence, that it should capture as completely as possible, to be reliable in the sense that its reproduction in similar conditions should lead to similar results and to present a trait named construct validity. The latter refers to the capacity of the test employed to really capture the competence it is designed to assess, having in mind that some of the competences that need to be assessed are not directly observable. This phase can be easily linked to the summative assessment concept. A second phase in the assessment of learning process corresponds to the rethinking of the concept of competence which from "a set of independently measurable traits" became "a combination of competency domains or competencies". The new paradigm places much emphasis on general traits such as independence, thoughtfulness, critical thinking, that cannot be directly observed throughout summative assessment. Therefore, the assessment strategy should take into consideration the strengths and weaknesses of each assessment method and the result to be in accordance with the type of methods used and their limits in evaluating the competences that need to be assessed. Van der Vleuten (1996) identifies five aspects that have to be considered when choosing an assessment method in order to fully

DOI: $10.2478 /$ picbe-2020-0048, pp. 514-520, ISSN 2558-9652| Proceedings of the $14^{\text {th }}$ International Conference on Business 
understand its strengths and weaknesses: reliability, validity, educational impact, cost effectiveness and acceptability. However, in practice, the focus remained on assessing independent and stable traits and the requirement that a method to be used to assess an independent trait. The third phase is the assessment as a programme. It corresponds to the present period that requires a detailed planning of the assessment of learning process under a form of a programme that allows holistic evaluations and the compensation between partial grades. As Le Boterf (2010)(in Calenda and Tamaro, 2015) states, what we expect today from a person is to be able to use his own resources and the contextual ones and to expand them in order to solve a precise task. Thus, assessing a competence requires to verify the following aspects: "to know how to act, to want to act and to be able to act". Considered in this form, the holistic assessment is based not on assessing each independent competence, but merely the overall result generated by the particular combination of competences and contextual features that characterizes the learner at a specific moment.

This last phase is also related to the emergence of a new concept, namely the assessment for learning or formative assessment. It corresponds to the need of widening the assessment objectives, focusing less on establishing minimal standards for a student to pass the exam or on the necessity of ranking students, which however remain extremely important in some occasions, and more on using the evaluation results to make changes in the teaching process or to obtain specific information on where to focus the effort of each learner in order to perform optimally.

The concepts of feedback and correctives stand in the centre of the assessment for learning process (Wiliam, 2011). In its most general definition, the feedback represents "the information on the gap between the present state of a given system and the intended one". The formative assessment or the assessment for learning implies according to Wiliam (2011) that the assessment methods and techniques should be particularly defined in order to get specific information on what is to be done in order to improve performance and how is it to be done. Moreover, the author stresses on the fact that the process has to be continued by a follow-up phase in which the measures deemed necessary according to the results of the assessment for learning to be implemented and controlled in order to verify if the expected improvement occurs. Regarding the methods to be employed in the assessment for learning process, the literature remarks that unlike the summative assessment, the formative one offers broader roles to many categories of participants. Hence, the classical assessment by the teacher can be supported by other types of assessment such as peerassessment and self-assessment, with clear complementary advantages. The peer-assessment for example allows obtaining supplementary information due to a smaller degree of inhibition that the subjects elicit towards their peers, while the self-assessment has clear advantages in terms of allowing the learner to become more conscious of the breaches in the individual learning process and on how to act in order to overcome them. In Kahl (2005), The formative assessment is defined as "a tool that teachers use to measure student grasp of specific topics and skills they are teaching. It's a 'midstream' tool to identify specific student misconceptions and mistakes while the material is being taught'.

The definition of the term 'assessment for learning' is not yet widely accepted by all scientists in the field. Some of them make a clear distinction between the terms 'assessment of learning' and 'assessment for learning' in the sense that the goal in the first process is to obtain a clear measurement of the extent of the learning process and/or a reliable ranking of the learners, while the other only has informational purposes for the teachers in order to adapt the teaching process and have absolutely no implication in terms of grades or students' future accession to a

DOI: $10.2478 /$ picbe-2020-0048, pp. 514-520, ISSN 2558-9652| Proceedings of the $14^{\text {th }}$ International Conference on Business Excellence 2020 
certain status. Others have a more general view (see Wiliam, 2011) considering that no matter the form of the assessment and the different goals it assumes, it can become formative if conclusions are drawn and implemented in order to improve the learning process. The present paper favours the last approach and considers that the assessment for learning can be seen a special form of assessment of learning, consciously designed in order to gather and use detailed information on how to improve the learning process. Andersson et al. (2019) takes a step forward comparing two 'forward-looking assessments', namely the formative assessment and the response to intervention. If the first one is clearly designed to obtain information on how to improve teaching and the learning process generally speaking and is characterized by a specific design without which gathering the information necessary for the improvement would not be possible, the response to interventions is a method that allows the teacher to adapt to the students' needs based on the students' previous interventions.

Although significant work has been done in the sense of emphasizing the 'assessment for learning' in theoretical studies, an important work is still to be done to implement it in practice (Kippers et al., 2018). However, some scientific studies based on interviews among teachers show that teacher education processes enhance the knowledge of the teachers in terms of modern assessment methods and facilitates their implementation in practice (Badia and ChumpitasCampos, 2018).

\section{Methodology}

The paper makes a synthetical analysis of the previous literature on the assessment of learning used as a documentary basis for offering throughout scientific inference an answer to a very important a actual question in the modern educational system: "Which should be the optimal combination of assessment methods in order to optimize the learning process?'.

The paper has a particular focus on the higher education system and puts in evidence throughout an argumentative process the factors that influence the choice of the assessment methods considering the present educational environment.

\section{Results and discussions}

\section{Assessment methods and their use in the assessment for learning in higher education}

With such a rich literature on the assessment of learning in higher education, the teachers are constantly trying to find the most suitable way to assess the students' achievements. Multiple types of assessment are available: the written exam (on paper or on a computer), the oral exam, the practical exam.

The choice between these general types differ according to the kind of competences that need to be assessed, the goals of the assessment process, but also to the conditions available for the examination process. Whatever type is chosen, it has to be previously commented with the students, so they can extract the best of the results obtained in terms of adjustments necessary to improve the learning process.

In the framework proposed by Van der Vleuten (1996), each examination type has advantages and disadvantages, most of them being contextual.

For example, in a national examination such as in the economic higher education, a matrix of weaknesses and strengths is presented in the table below.

DOI: $10.2478 /$ picbe-2020-0048, pp. 514-520, ISSN 2558-9652| Proceedings of the $14^{\text {th }}$ International Conference on Business 
Table 1. The matrix of weaknesses and strengths of different assessment methods in economic higher education in Romania

\begin{tabular}{|l|c|c|c|c|c|}
\hline $\begin{array}{l}\text { Examination } \\
\text { type }\end{array}$ & reliability & validity & $\begin{array}{l}\text { educational } \\
\text { impact }\end{array}$ & $\begin{array}{l}\text { cost } \\
\text { effectiveness }\end{array}$ & Acceptability \\
\hline $\begin{array}{l}\text { Written } \\
\text { exam }\end{array}$ & + & + & - & + & + \\
\hline Oral exam & + & + & $\begin{array}{c}+ \\
\text { (if feedback } \\
\text { is provided) }\end{array}$ & $\begin{array}{c}- \\
\text { (too many } \\
\text { students) }\end{array}$ & (subjectivity) \\
\hline $\begin{array}{l}\text { Practical } \\
\text { exam }\end{array}$ & + & - & + & $\begin{array}{c}- \\
\text { (too many } \\
\text { students and } \\
\text { too costly) }\end{array}$ & $\begin{array}{c}\text { (legal issues, } \\
\text { subjectivity, } \\
\text { duration) }\end{array}$ \\
\hline
\end{tabular}

PICBE | 518

Please bear in mind that most final exams have as main purpose to rank the students upon the degree they acquired specific economic knowledge during the bachelor courses. The chosen type would be in this case the written exam, which corresponds to the common practice in many countries nowadays because it comports the highest number of strengths. However, for specific subjects where acquiring the practical skills necessary is the most important objective and legal matters are simpler, the practical exams are often preferred (se for example, the disciplines related to informatics skills).

It is straightforward that the appropriate type would be different, if for example, the examination will aim to assess the argumentative skills of the students or their easiness to make a public discourse.

Besides this general classification, each type of examination can employ several methods. For example, the written exam can be composed of multiple-choice items, open-ended questions, or essays. The oral exam can take the form of an interview or of a lecture (speech) on a given subject. In the case of a practical exam, it may be represented by a simulation or by a mere practical implication of the subject in the current activity (see the driving license exam).

Each method can be also analyzed in terms of how well it performs for the assessment of a specific set of competences For example, the multiple-choice items are suitable for verifying a wide range of theoretical subjects in a small span of time, because the answers are pre-defined and it takes a short time for a student to choose the answer assumed to be correct (see Butler, 2018). However, this method performs badly if the capacity of taking complex decisions is tested, as it fails to create complex frameworks and to allow the provision of arguments. In this case, the openended questions are more appropriate.

In the same line of reasoning, the speech will not be used if the assessed competence is the ability to interact with others. The simulation can be the best (sometimes, the unique) method for complex tasks assessment, while a practical test in real conditions may be the best method for assessing body preparation skills, for example.

When establishing the strategy for an assessment sequence, the teacher considers the advantages and limits of each method and the specific goals and conditions of the assessment. A 
short non-exhaustive review of the common factors that influence the assessment strategy and methods are presented below.

\section{Factors that influence outcome in the assessment of learning in the higher education system}

The choice of the assessment strategy and methods is highly influenced by internal and external

PICBE | 519 factors and one must understand the complexity of the environment in which an assessment of learning takes place before making the best decision about what type and methods will fit best for that specific assessment.

Some of the factors that have an influence on the choice of the assessment strategy are intrinsic to the learning process. Such factors are the type of competences to be assessed (theoretical or practical, for example), the main goals of the assessment process (summative or formative purposes, mainly). The previous subchapter shed a light on how these factors influence the assessment strategy.

Other factors are external to the learning process, but still remain extremely important for the assessment strategy. The administrative factors, for example are extremely important. Among these factors, a limited time frame for an exam established by the executive board (either a minimal period of examination, or a maximal one) can have a huge impact on the type of examination chosen (one cannot undertake an oral exam that lasts 2 hours per person, nor an oral exam with one hundred students in less than three hours due to the limited availability of the suitable rooms for such an activity in the university).

In other cases, the period left for the teacher to grade the exams before being obliged to announce the results have a role to play in choosing the assessment strategy. If the teacher feels that there is not enough time for grading, the multiple-choice tests are likely to be chosen, either for the entire exam or in combination with open-ended questions, because they shorten the grading procedure.

Also, the costs of the materials can be a limiting factor in practical examinations, in this case the choice being made either in terms of choosing the subjects that imply the smaller cost of the material per student, or in terms of changing the assessment type towards a written exam, for example. Of course, the effects may not be similar in terms of educational support, but the method will definitely score better in term of cost effectiveness.

Other limitations may refer to the composition of the jury in oral or practical examinations in terms of minimal number of members of the teaching staff and their domains of expertise, that can limit the extent of using oral examinations in practice or to the need of keeping objective evidences of the way the exam takes place, that can be limiting in case of oral examinations.

As a main conclusion, administrative factors clearly impose limits in the choice of the assessment strategy, but they may be useful in the relation of the institution with various stakeholders and cannot be ignored.

\section{Conclusion}

This paper shed a light on the complexity of the assessment for learning in higher education. It put forward that the goals of the assessment are important and how they are established considering the evolution of the purpose and mission of the higher education. It particularly dealt with how the concept of competence evolved and became the core of the learning and assessment processes. In

DOI: $10.2478 /$ picbe-2020-0048, pp. 514-520, ISSN 2558-9652| Proceedings of the $14^{\text {th }}$ International Conference on Business 
the same line of reasoning, the concept of assessment for learning was presented and its importance in the modern education throughout of a literature review on the subject.

From a practical point of view, the paper makes a review of the examination types and methods and suggests using the framework proposed by van der Vleuten (1996) to choose the best combination possible, emphasizing that the choice of the examination type and methods is contextual and depends on factors from inside and outside the learning process.

PICBE | 520

\section{References}

Andersson, U., Lofgren, H., Gustafson, S. (2019). Forward-looking assessments that support students' learning: A comparative analysis of two approaches. Studies in Educational Evaluation, 109-116.

Badia, A., Chumpitaz-Campos, L. (2018). Teachers learn about student learning assessment through a teacher education process. Studies in educational Evaluation, 58, 1-7.

Butler, A. (2018). Multiple-Choice Testing in Education: Are the Best Practices for Assessment Also Good for Learning?. Journal of Applied Research in Memory and Cognition, 7, 323331.

Calenda, M., Tammaro, R. (2015). The assessment of learning: from competence to new evaluation. Procedia - Social and Behavioral Sciences, 174, 3885-3892.

Kahl, S. (2005). Where in the world are formative tests?Right under your nose!. Education week, 25(4), 11.

Kippers, W., Wolternick, C., Schildkamp, K, Poortman, C., Visscher, A. (2018). Teachers' views on the use of assessment for learning and data-based decision making in classroom practice. Teaching and Teacher Education, 75, 199-213.

Calenda, M., Tammaro, R. (2015). The assessment of learning: from competence to new evaluation. Procedia - Social and Behavioral Sciences, 174, 3888.

Lile, R., Bran C. (2014). The assessment of learning outcomes. Procedia-Social and Behavioral Sciences, 163,125-131.

Schuwirth, L., van del Vleuten, C. (2018). How ‘Testing' Has Become 'Programmatic Assessment for Learning'. Health Professions Education, in press.

Van der Vleuten, C. (1996). The assessment of professional competence: development, research and practical implications. Advances in Health Scientific Education, 1(1), 41-67.

Wiliam, D. (2011). What is assessment for learning? Studies in Educational Evaluation, 37, 3-14. 